

CHALMERS

UNIVERSITY OF TECHNOLOGY

\title{
Numerical Analysis of Aerodynamic Impact on Passenger Vehicles during Cornering
}

Downloaded from: https://research.chalmers.se, 2023-04-26 06:22 UTC

Citation for the original published paper (version of record):

Josefsson, E., Hagvall, R., Urquhart, M. et al (2018). Numerical Analysis of Aerodynamic Impact on Passenger Vehicles during Cornering. SAE Technical Papers, 2018-May(May).

http://dx.doi.org/10.4271/2018-37-0014

N.B. When citing this work, cite the original published paper. 


\title{
Numerical analysis of aerodynamic impact on passenger vehicles during cornering
}

\author{
Erik Josefsson, Robin Hagvall, Magnus Urquhart, Simone Sebben \\ Chalmers University of Technology, Sweden
}

\begin{abstract}
Governmental regulations and increased consumer awareness of the negative effects of green-house gases has led the automotive industry to massive invest in the energy efficiency of its fleet. One way towards accomplishing reduced fuel consumption is minimizing the drag of vehicles by improving its aerodynamics. Fuel consumption is measured by standardized driving cycles which do not consider aerodynamic losses during cornering. It is uncertain whether cornering has a significant impact on the drag, and the present study intends to investigate this numerically, using a generic vehicle model called the DrivAer. The model is considered in two different configurations: the notchback and the squareback. Cornering in various radiuses is modelled using a Moving Reference Frame approach which provides the correct flow conditions when simulating a stationary vehicle where the wind and ground are moving instead. Simulations are also performed for straight ahead driving conditions to provide data for comparison to a cornering vehicle.
\end{abstract}

Results indicate that the drag increases when the cornering radius is small. This implies a higher fuel consumption than the standardized driving cycles suggest using straight-ahead drag coefficients. The detailed underbody of the DrivAer model is not symmetrical which, for large turning radiuses, results in a decrease of drag for left turns, while turning right results in an increase of drag. Cornering affects the squareback and the notchback similarly, although the squareback experiences a slightly higher drag throughout the cases investigated.

\section{Keywords}

Vehicle aerodynamics, CFD, DrivAer, cornering, drag force, driving cycles

\section{Introduction}

Road transportation is today responsible for one-fifth of the total carbon dioxide emissions in the EU [1]. One step towards reducing those emissions is by reducing the fuel consumption for passenger vehicles, and since drag force is a major factor, this can be accomplished by aerodynamic improvements.

Fuel consumption is measured with standardized driving cycles such as Worldwide harmonized Light vehicles Test Procedures (WLTP) [2]. The WLTP cycle only considers flows in the driving direction of the vehicle, however, studies in simplified geometries have shown that aerodynamic properties can be affected by cornering [3],[4]. Keogh [3], for instance, studied the impact of cornering on an inverted wing and found significant changes in the flow structures. It is therefore of interest to analyze the influence cornering could have on cars, to see if it is a matter worth considering when designing vehicles.
Attempts have been conducted to reproduce cornering physically by, for instance, placing a vehicle sideways in a wind tunnel. This is a major simplification that does not capture the essence of cornering, a curvature of the freestream flow. Another approach is to use a curved test section [4], however, this also fails to reproduce the flow conditions as in actual cornering as it gives rise to pressure gradients between the walls. There are other aggravating factors with physical tests due to the dynamics that arise when cornering, such as roll, body slip and steering angles with rotating wheels.

In this study, the aerodynamic impact on a passenger vehicle during cornering is investigated numerically, in steady-state conditions, using Computational Fluid Dynamics (CFD). Steady-state conditions are assumed as a first attempt to analyze the importance of considering cornering and its influence on the aerodynamic drag and lift. Firstly, a simulation is performed to model straight-ahead driving, as a reference case for comparison. After that, cornering is modelled using a Moving Reference Frame (MRF) approach. The different cornering radiuses considered are 100, 200, 400 and $800 \mathrm{~m}$, for both left and right turns. The velocity is set to $90 \mathrm{~km} / \mathrm{h}$ throughout the simulations. The generic vehicle model DrivAer [5] is used in the study with two different configurations: squareback and notchback. The underbody of the model is detailed and the wheels have open rims. The front cooling is tapered (closed cooling) and there is no engine bay present. Vehicle dynamics that occur when cornering, such as roll, body slip and steering angles will be taken into account in the study.

\section{Methodology}

\section{Curved Drag Force}

Since the vehicles velocity vector is not constant over the entire body while cornering, the drag force calculation needs to be modified. The drag force is calculated as [4]

$$
F_{D}=\left(P A_{x}+\tau_{x}|A|\right) \cos \xi+\left(P A_{y}+\tau_{y}|A|\right) \sin \xi,
$$

where $P, A$ and $\tau$ denote the pressure, area and shear stress for the specific cell. $\xi$ denotes the angle between the point where the flow is parallel to the vehicle, the positions of the cell and the center of the corner. The contribution from each cell is then summarized to obtain the total drag force. The area used to calculate the drag coefficient is the projected area of DrivAer from the front in the straight-ahead case, $A_{p}=2.163 \mathrm{~m}^{2}$, even though it varies a little between the cases due to body slip. The area is the same for the notchback and the squareback.

\section{Geometry}

DrivAer is a generic vehicle model, with the shape of an Audi A4 and a BMW 3-series combined [5]. It possesses details such as mirrors, windows, door handles and an optional detailed underbody. DrivAer is 
available in various coachwork configurations, of which the squareback and notchback are used in this study. Those are equipped with open rims, closed cooling and detailed underbody, see figure 1 . Note that the underbody makes the geometry non-symmetrical.
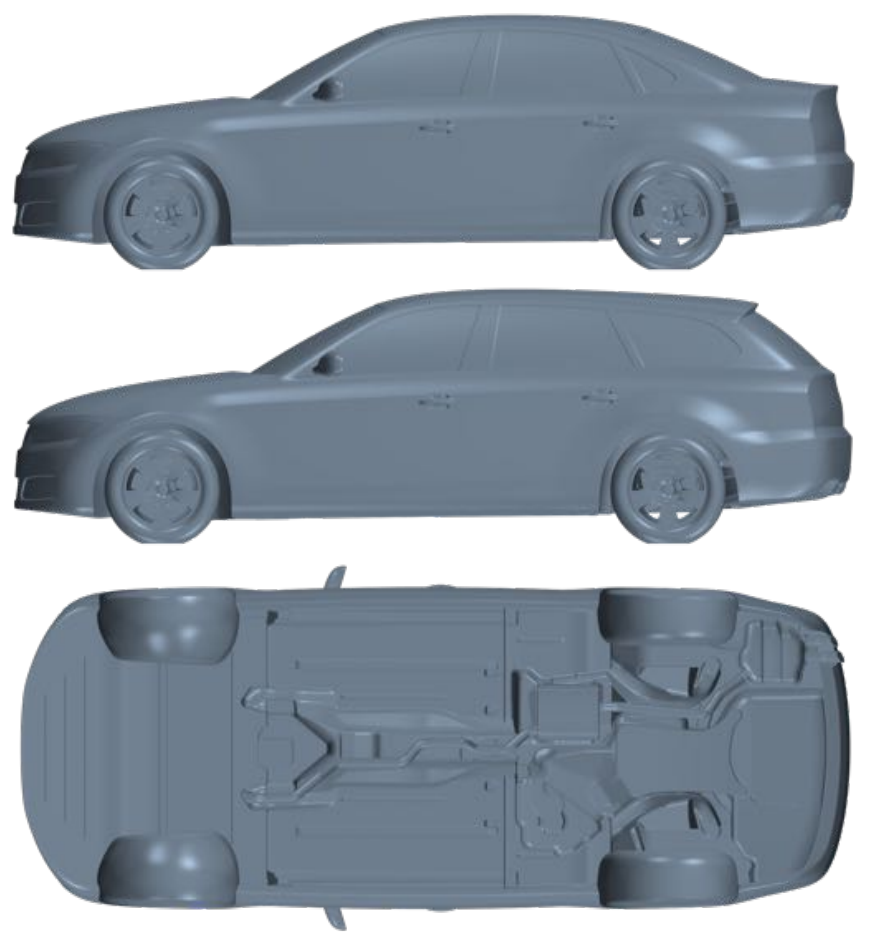

Figure 1: The two configurations of DrivAer that are considered. The notchback and the squareback, both equipped with the detailed underbody as shown.

\section{Domain}

The curve radiuses that are treated in this study are 100, 200, 400 and $800 \mathrm{~m}$. For each one of those a domain is constructed with its particular curvature. A domain without curvature is also created for the straightahead case. In order to avoid gradients at the walls, the dimensions of the domains are specified to $64 \mathrm{~m} \times 18 \mathrm{~m} \times 10 \mathrm{~m}(\mathrm{~L} \times \mathrm{W} \times \mathrm{H})$, where the length is measured for the center line. DrivAer is placed in a way so that five car lengths are obtained in front of DrivAer and eight are obtained behind [6]. In figure 2 the domain with radius $200 \mathrm{~m}$ is shown, as well as the defined coordinate system. In addition to the curved drag force the side and lift force are examined. These are defined as positive along the $y$ - and $z$-axis, respectively.

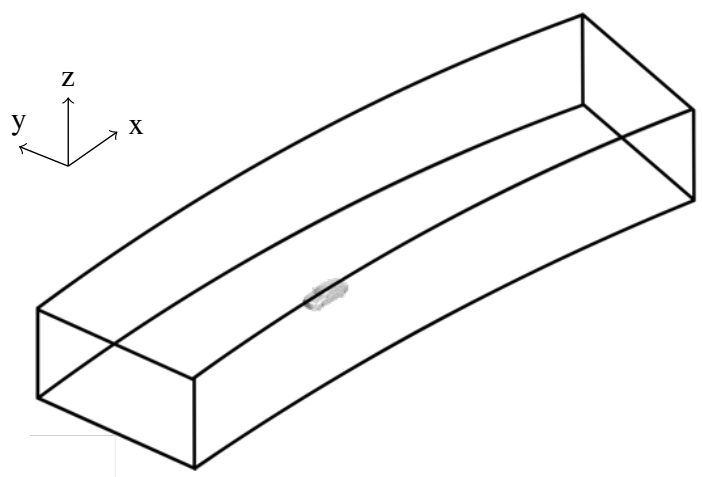

Figure 2: The domain for a left turn with curve radius $200 \mathrm{~m}$, and the defined coordinate system.

\section{Vehicle Dynamics}

In order to obtain more realistic results, some vehicle dynamic effects are taken into account when cornering is modelled. Cornering gives rise to a lateral acceleration towards the center of rotation, which in turn gives rise to a roll angle of the vehicle. This results in the vehicle being tilted outwards from center of rotation. The other effects that are considered are the body slip angle, which is difference in vehicle and traveling direction, and the steering angles for the wheels. All the angles above are calculated according to Jacbosson [7], where the physical parameters are assumed based on similar vehicles. All parameters can be found in table 1 .

Table 1: Parameters used to calculate roll, body slip and steering angles.

\begin{tabular}{ccc}
\hline Parameter & Values & Origin \\
\hline Mass & $1500 \mathrm{~kg}$ & Assumed \\
Mass distribution (front/rear) & $52 / 48$ & Assumed \\
Distance between axles & $2.786 \mathrm{~m}$ & Measured \\
\hline
\end{tabular}

The axis from which the roll angle is defined is located three quarters track width from the inner wheel track and at the height of the center of the wheels, from recommendations by Milliken and Milliken [8]. The angles for all cases are shown in table 2 .

Table 2: Roll, body slip and steering angles for each case, the dynamical effects that are being considered when modelling cornering.

\begin{tabular}{cccc}
\hline Radius $[\mathrm{m}]$ & Steering angle $\left[{ }^{\circ}\right]$ & Slip angle $\left[{ }^{\circ}\right]$ & Roll angle $\left[{ }^{\circ}\right]$ \\
\hline 100 & 1.65 & 3.07 & 3.00 \\
200 & 0.83 & 1.50 & 1.50 \\
400 & 0.41 & 0.77 & 0.75 \\
800 & 0.21 & 0.39 & 0.38 \\
\hline
\end{tabular}

\section{Moving Reference Frames}

In reality cornering is equivalent to a curvature of the freestream flow, which means that the tangential velocity is not constant along the width of the car. Having the geometry move in CFD would be expensive, so instead a Moving Reference Frames (MRF) approach is used to reduce complexity. This is a method used to simulate rotationally symmetric objects, such as propellers. By using MRF, a movement in a part of a geometry can be simulated with a stationary mesh [9]. In this way, some transient sequences can be modelled with a stationary solution. For a rotating reference frame, the velocity is related to the stationary reference frame according to

$$
\mathbf{V}_{0}=\mathbf{V}_{R}+\boldsymbol{\Omega}_{R} \times \mathbf{r}
$$

where 0 and $R$ denote the stationary and the rotating reference frames respectively and $\boldsymbol{\Omega}$ is the angular velocity vector. For a constant angular velocity the Navier-Stokes equations become

$$
\begin{aligned}
\rho\left(\frac{\partial}{\partial x_{j}}\left(V_{R, i} V_{R, j}\right)\right. & \left.+2 \varepsilon_{i j k} \Omega_{j} V_{R, k}+\varepsilon_{i j k} \Omega_{j} \varepsilon_{k l m} \Omega_{m}\right)= \\
= & -\frac{\partial p}{\partial x_{i}}+\mu \frac{\partial^{2} V_{R, i}}{\partial x_{j} \partial x_{j}} .
\end{aligned}
$$

In this case it in principal means that the "fluid" is standing still, while the domain, containing DrivAer, rotates around the center of rotation. This way the curvature of the freestream flow is captured. In order to model rotating wheels, the volumes between the spokes are treated in the same way, but the reference frames for each wheel are defined relative to the reference frame modelling cornering. 


\section{Mesh and Mesh Study}

The mesh consists of approximately 65 million cells which are hexahedral dominant. In addition to this, some areas around DrivAer with complex geometry and flow are refined further. The refinements are isotropic and related to the distance $84 \mathrm{~mm}$. In a volume covering DrivAer and stretching 2.5 car lengths behind, the cells side length is decreased by a fourth. Further refinements are made between the ground and the underbody, around the wheel houses, in the wake and at the front of DrivAer. In those areas the side length is decreased with an eighth. Finally, around the separation point the side length is decreased by a sixteenth. The mesh is shown in figure 3 . Three prism layers are constructed next to the surface of DrivAer, where the center point of the first prism cell is located in $y=2.2 \mathrm{~mm}$, which gives the sought $30<y^{+}<200$.

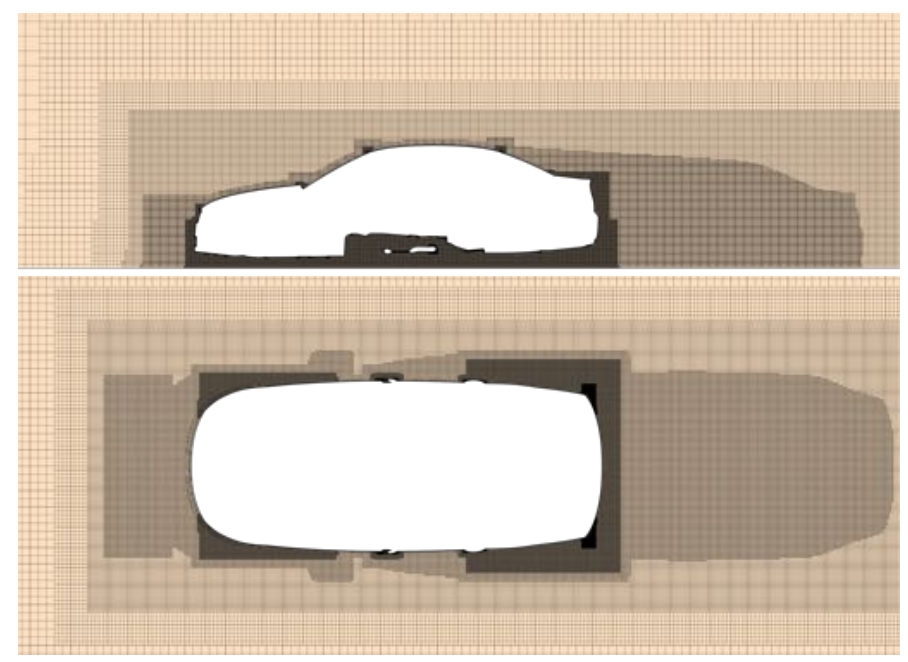

Figure 3: Final mesh for notchback, seen from the side and from above, and containing approximately 65 million cells.

To ensure that mesh convergence is reached, three meshes are created, consisting of 40, 60 and 80 million cells. They are all studied for the straight-ahead case with the notchback, where the change of drag is the deciding factor. Between the two lowest dense meshes $(40,60)$ and the highest dense mesh (80) the difference in drag is between 10 and 15 counts. By adding additional refinements to the 60 million cells mesh a 65 million cells mesh where obtained which differed approximately 2 counts from the 80 million cells mesh. This mesh was therefore considered converged.

\section{Simulation Set-up}

All simulations are run in steady state conditions in the CFD software StarCCM+ using $k-\varepsilon$ as the turbulance model. The boundary conditions for the domain and the different parts of DrivAer for the straight-ahead cases are shown in table 3 .

For the cornering cases the inlet and floor velocity are set to zero. Instead the whole domain is placed in a reference frame rotating around the corner center. The other boundary conditions are kept the same as in the straight-ahead case (table 3).

The simulations are run until the drag coefficient fluctuate less than 1 count $\left(1\right.$ count $\left.=0.001 C_{D}\right)$ for 500 iterations and the residuals for turbulent dissipation rate, turbulent kinetic energy, momentum and continuity have decreased at least four orders of magnitude.
Table 3: The defined boundary conditions for the domain and the different parts of DrivAer for the straight-ahead cases.

\begin{tabular}{ll}
\hline Boundary & Condition \\
\hline Inlet & Velocity inlet $[25,0,0] \mathrm{m} / \mathrm{s}$ \\
Outlet & Pressure outlet, $0 \mathrm{~Pa}$ \\
Inner side & Symmetry \\
Outer side & Symmetry \\
Floor & Wall, $[25,0,0] \mathrm{m} / \mathrm{s}$ \\
Roof & Symmetry \\
Wheels \& Rims & Wall, rotating around wheel axle, $78.5 \mathrm{rad} / \mathrm{s}$ \\
Remaining model & Wall \\
\hline
\end{tabular}

\section{Results}

The results are divided into three main subsections: the effects of cornering compared to straight-ahead driving, the difference in drag between right and left turns, and the difference in drag between the notchback and the squareback. Primarily the source for difference in drag is investigated, but trends for side and lift forces are also discussed. All force coefficients from all simulations are shown in table A1 in the appendix.

\section{Influence of Cornering}

Comparing cornering and straight-ahead driving significant differences in the flow are noted. For the notchback, straight-ahead driving results in a drag force coefficient, $C_{D}$, of 288 counts. Comparing this to turning right with a corner radius of $400 \mathrm{~m}$, cornering results in an increase of $C_{D}$ by 28 counts, or $9.7 \%$. This can partly be explained by the change in base pressure, as seen in figure 4 . Comparing the cases, an over all lower pressure is obtained for the straight-ahead case, explaining the increase in drag. It is worth noting that the base pressure is asymmetrical for both cases and that, for the cornering case, the asymmetrical characteristics tend to be more visible, therefore it is motivated to further investigate the influence of the turning direction.

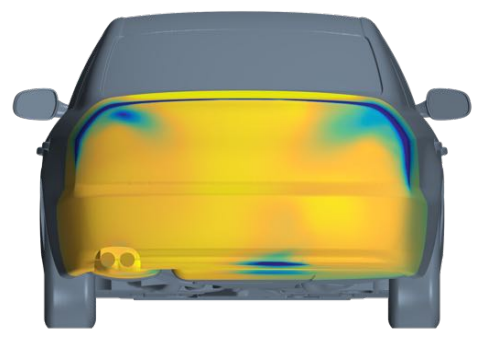

(a) Straight ahead

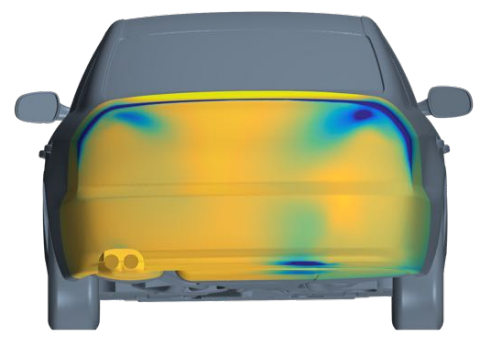

(b) Right turn, radius $400 \mathrm{~m}$

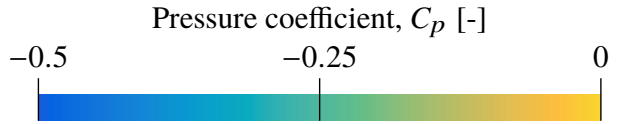

Figure 4: Base pressure on notchback for straight-ahead driving (a) and turning right with $400 \mathrm{~m}$ radius (b) 
Difference in accumulated drag, $\Delta C_{D}$, compared to straight driving

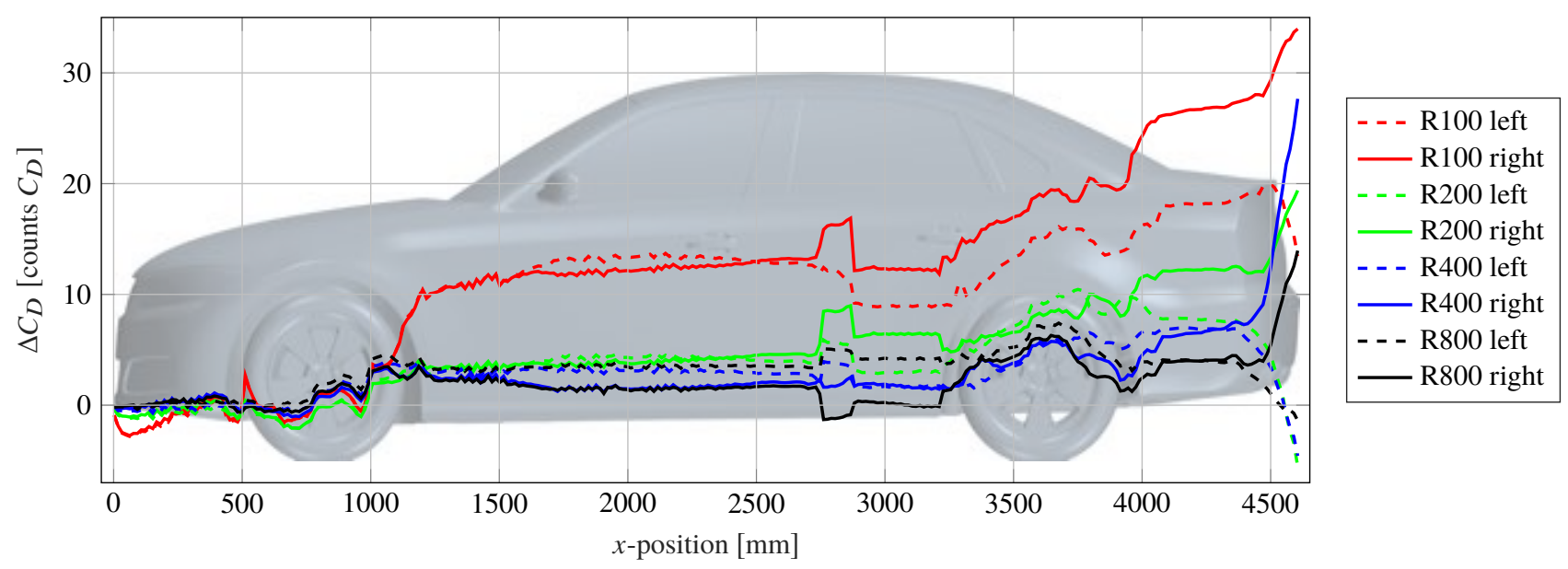

Figure 5: The accumulation of difference in drag along DrivAer between all cornering cases and the straight-ahead case for the notchback configuration.

\section{$C_{D}$ left and right turn compared to straight}

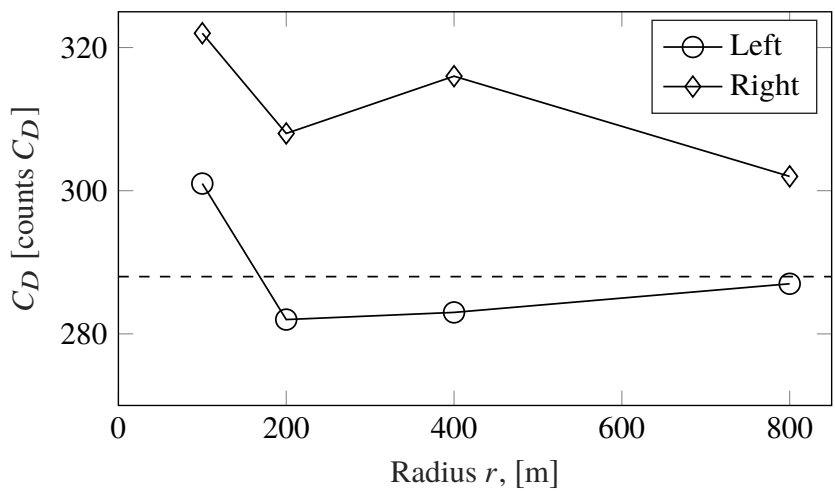

Figure 6: Drag force coefficient for all cornering radiuses and both turning directions for the notchback. The dashed line is the straight-ahead case.

\section{Turning Direction}

In this subsection, the difference in drag depending on the turning direction is investigated for the notchback. The drag force coefficient for different corner radiuses and both turning directions is showed in figure 6, where the dashed line represents the straight-ahead case. As the turning radius increases, the different turning directions respond differently for curve radiuses 200 to $800 \mathrm{~m}$. Turning right results in an increase in drag, while turning left result in a decrease in drag, compared to straight-ahead driving. These results were not expected at first and therefore it is investigated further.

Investigating the drag on different parts of the car, it can be seen that the difference in drag is primarily found at the back of the underbody and at the rear end. This can be seen in figure 5, which shows how the difference in drag between the cornering cases and the straight-ahead case accumulates along the DrivAer for both turning directions. The same pattern is seen for all radiuses, where both left and right turns increases drag similarly for $x<4.4 \mathrm{~m}$. Rearwards the different turning directions gives opposite effect. The largest difference in drag between the turning directions is seen for curve radius $400 \mathrm{~m}$, where the drag decreases $2 \%$ for the left turn and increases $10 \%$ for the right turn. Therefore, the base pressure for these cases are examined. In figures 7 (a) and 7(b) the pressure coefficient, $C_{p}$, is shown for curve radius 400 $\mathrm{m}$ for left and right turns, respectively. It can be seen that the pressure differs between the two cases. For the right turn, the pressure is overall lower and somewhat more asymmetric than for the left turn. This effect is believed to be a major factor to the increased drag.

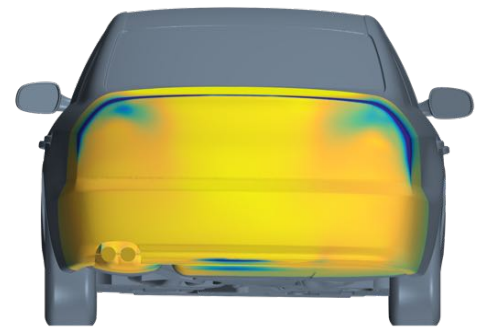

(a) Left

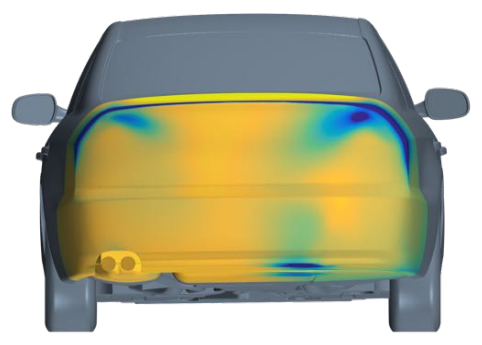

(b) Right

Pressure coefficient, $C_{p}[-]$

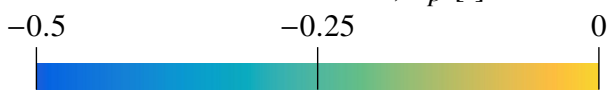

Figure 7: Base pressure for left (a) and right (b) turn with radius $200 \mathrm{~m}$.

Since the DrivAer is symmetric everywhere except at the underbody, it is the underbody which should be the reason for the difference in drag between left and right turns. Simulations conducted with a flat underbody showed no difference in drag for the two directions, as is expected. In the detailed underbody there is a diagonal channel for the exhaust pipe (see figure 1). Due to body slip, the channel aligns better with the flow when turning left, compared to a right turn. In figure 8 isosurfaces for $C_{p, t o t}=0$ are shown for the left and right turns with curve radius $400 \mathrm{~m}$. There is a clear difference in wake structure. Despite the difference in turning direction the wake seems to extend the furthest downstream behind the left most part of DrivAer, indicating the effect of the underbody. When turning right the exhaust pipe is less aligned with the flow then when turning left, which leads to a larger area with low velocity, resulting in a larger wake. 


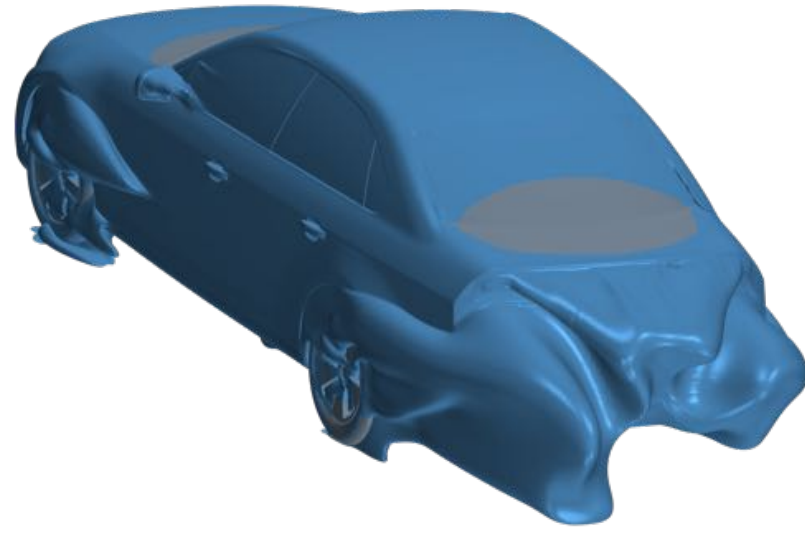

(a) Left turn

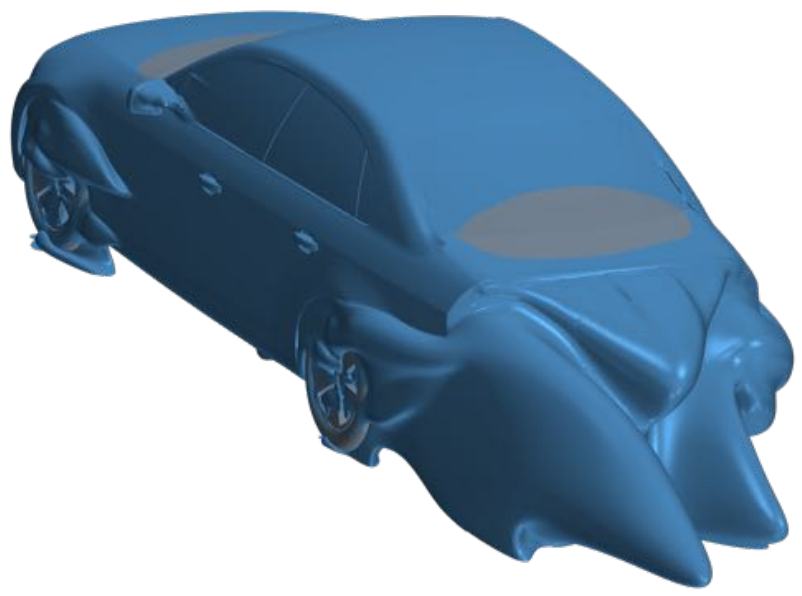

(b) Right turn

Figure 8: Isosurface for $C_{p, t o t}=0$ for left (a) and and right (b) turns with radius $400 \mathrm{~m}$.

In figure 9 , the lift force coefficient, $C_{L}$, for the notchback is shown for all cornering cases, with the dashed line representing the value for the straight-ahead case. As for the drag, the right turn gives the largest changes also for the lift force. The lift seems to peak around cornering radius $400 \mathrm{~m}$ for the right turn, while for the left turn, lift seems to continuously increase with increased radius. The lift is split into front and rear lift to investigate if cornering influences the lift balance of the vehicle. From figure 10 it can be seen that the force is directed downwards in the front and upwards in the rear. The dashed line is again the straight-ahead case. For both the front and the rear lift, the force dependency of curve radius is the about the same for both left and right turns. However, for both pair of wheels, it is noted that the right turn results in more lift then the left turns.

By examining the pressure coefficient at the underbody for curve radius $400 \mathrm{~m}$ (see figure 11) it can be seen that both turning directions results in a high pressure area in the proximity of where the exhaust pipe channel bends (see red markings in figure 11). This once again indicates that turning right seems to obstruct the airflow over the underbody more then when turning left. Since the high pressure area is larger for the right turn it explains part of the increase in lift. Another contribution to the difference can be seen at the rearmost where a higher pressure is obtained for the right turn then for the left turn. Similar behaviour is seen for all cornering radiuses examined.

\section{$C_{L}$ left and right turn compared to straight}

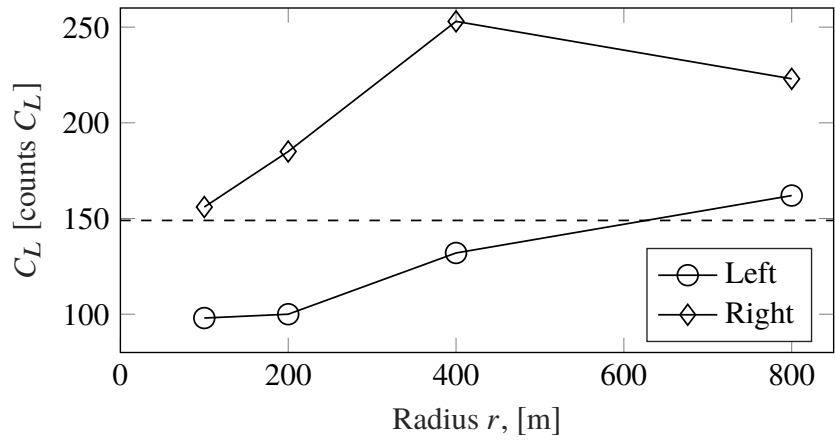

Figure 9: Lift force coefficient for all radiuses and turning directions for the notchback. The dashed line is the straight-ahead case.

$C_{L}$ for front and rear wheels, [counts $\left.C_{L}\right]$

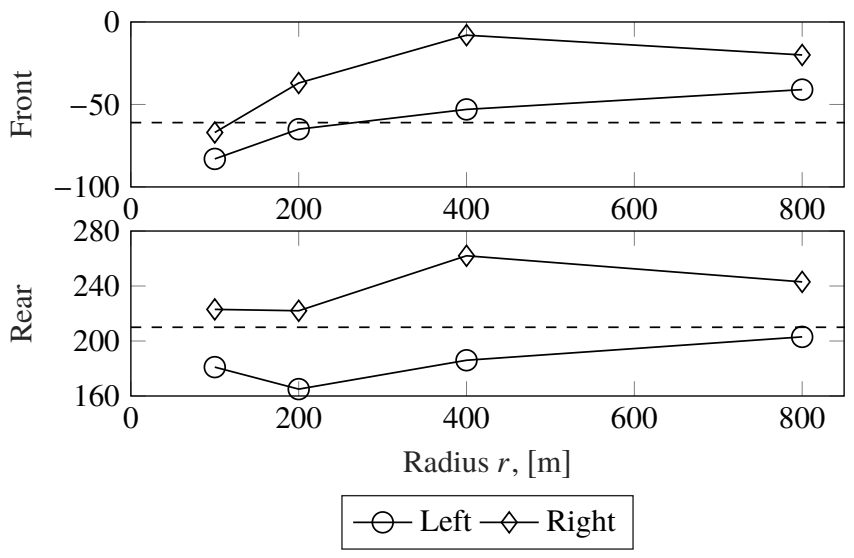

Figure 10: Lift force coefficient for all radiuses and both turning directions for the notchback for front and rear wheels. The dashed line is the straight-ahead case.

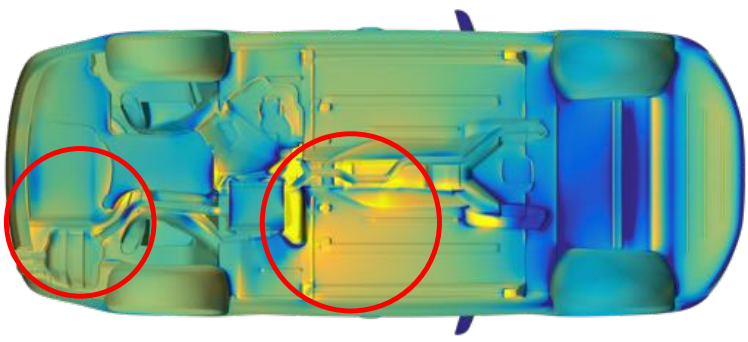

(a) Left

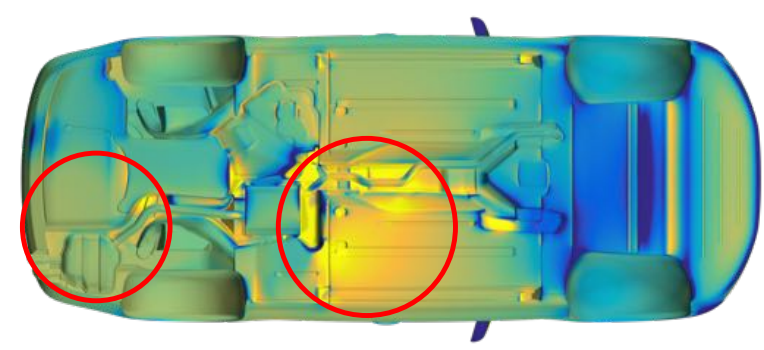

(b) Right

Pressure coefficient, $C_{p}[-]$

$-0.6 \quad-0.2$

0.2

Figure 11: Pressure coefficient at the underbody for left (a) and right (b) turn with curve radius $400 \mathrm{~m}$. The wheels are hidden. 
Looking at the side force coefficient in figure 12, it can be seen that the left turns diverge most from the straight-ahead case, while the right turns stay quite constant, and close to the value of straight driving. Note that the side force changes sign between the 100 and $200 \mathrm{~m}$ cases for the left turn. The side force is defined as positive in the $y$-direction according to figure 2 , and the coordinate system remains the same for both turning directions. Hence, for a left turn, a negative side force will be directed towards the corner centre, contributing to the car making the turn. This is the case for the $100 \mathrm{~m}$ radius left turn. For the remaining left turns, the side force will be directed outwards. For the right turns the force is directed towards the centre of the curve for all radiuses investigated.

In figure 13 the accumulation of side force for a corner radius $200 \mathrm{~m}$ is shown. At the front of the DrivAer, the side forces are similar for the different turning directions. Note that the side force here has been modified to be positive towards the center of the corner. Further downstream these similarities disappear. Instead an increase is obtained for the right turn and a decrease for the left turn.



Figure 12: Side force coefficient for all cornering radiuses and turning directions for the notchback. The dashed line is the straight-ahead case.

\section{Accumulated side force coefficient, $C_{S}$, for notchback}

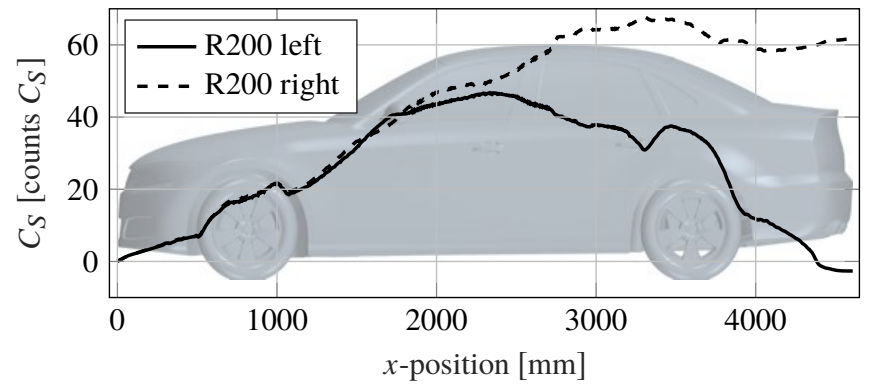

Figure 13: The accumulation of side force both turning directions with corner radius $200 \mathrm{~m}$. The sign of $C_{S}$ has here been modified so that, for both cases, a positive coefficient represents a force directed towards the center of the corner.

\section{Squareback Compared to Notchback}

This section compares the results obtained for the two DrivAer configurations with main focus on the left turn. The differnece in drag between the notchback and the squareback in straight-ahead conditions is 5 counts, with the latter having the higher value. In figure 14, the difference in drag between the straight-ahead case and the different curvatures is shown. The different configurations react similarly to decreasing curve radius, however, the squareback experiences higher drag throughout.
$C_{D}$ notch- and squareback compared to straight

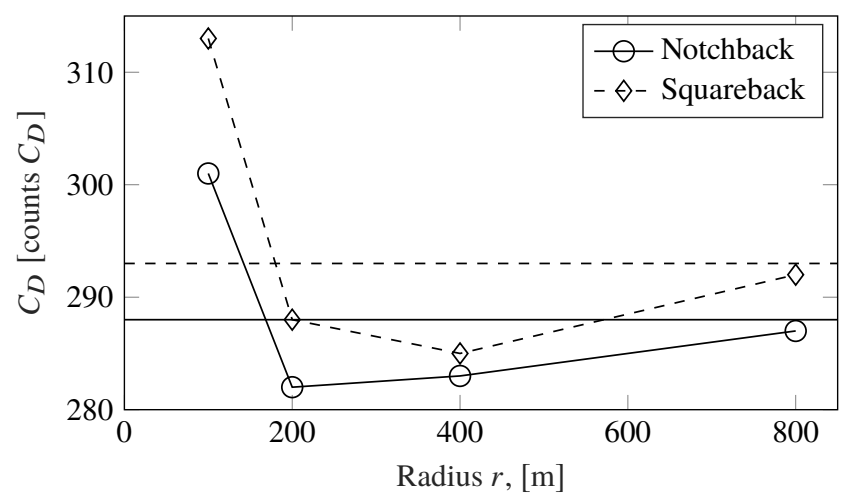

Figure 14: Drag force coefficient for all cornering radiuses comparing the notchback and the squareback. The horizontal lines are the straight-ahead cases.

Accumulated $\Delta C_{D}$ between notch- and squareback

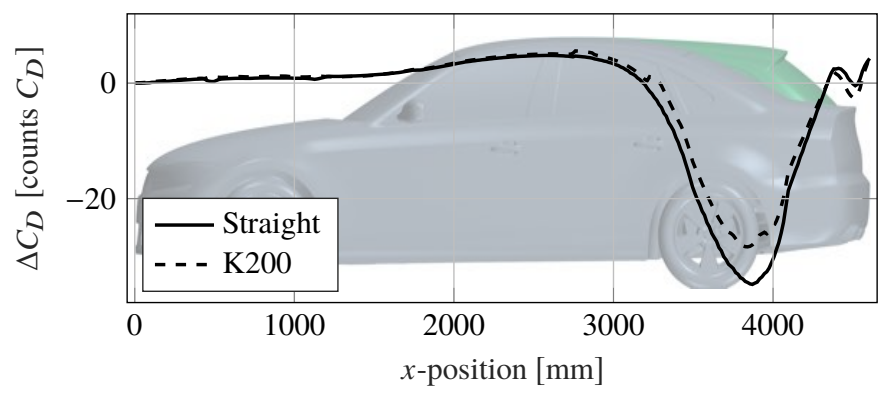

Figure 15: The accumulation of difference in drag between the notchback and the squareback for corner radius $200 \mathrm{~m}$ and straight-ahead driving.

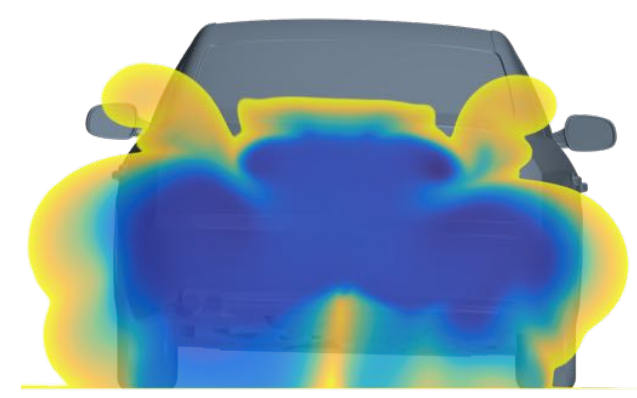

(a) Notchback

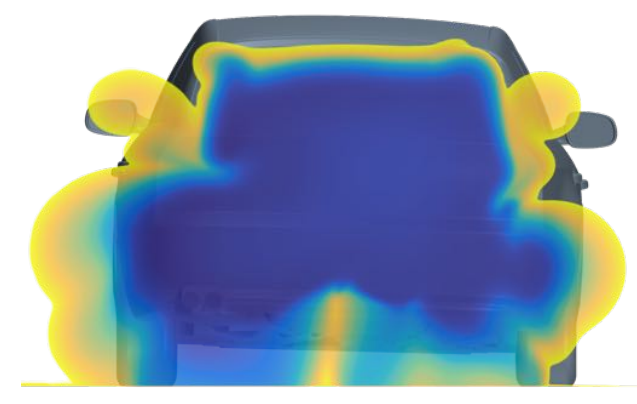

(b) Squareback

Total pressure coefficient, $C_{p, t o t}[-]$

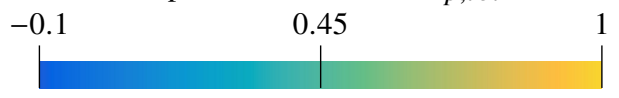

Figure 16: Total pressure coefficient $C_{\mathrm{p} \text {,tot }} 100 \mathrm{~mm}$ behind the rear of the notchback and the squareback turning left with curve radius $200 \mathrm{~m}$. 
$C_{L}$ notch- and squareback compared to straight

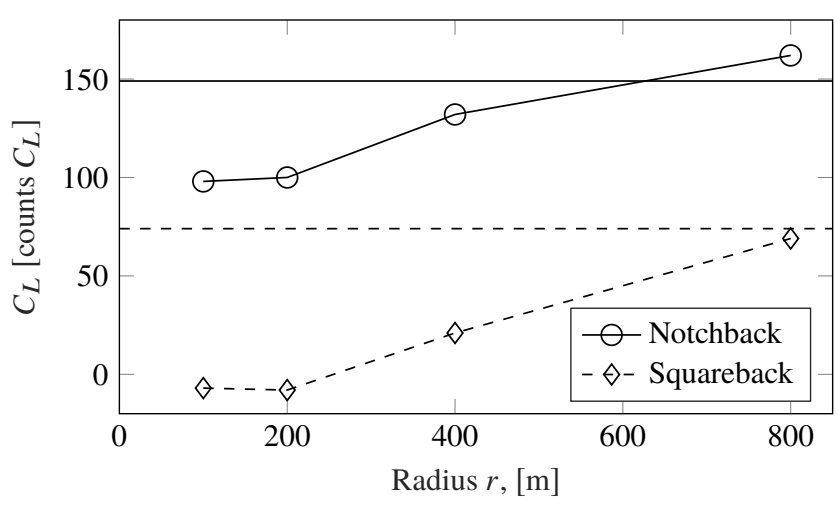

Figure 17: Lift force coefficients for all cornering radiuses for the notchback and the squareback. The horizontal lines are the straight-ahead cases.

In figure 15, the accumulated difference in drag between the notchback and the squareback is shown for straight-ahead driving and a corner radius of $200 \mathrm{~m}$. The pattern seen for $x>3.5 \mathrm{~m}$ is expected, since separation occurs later on the squareback. The same pattern is seen for all curve radiuses. Looking at this plot, it can be seen that the difference comes from the rear end type (notchback or squareback), rather than the wheelhouses or the underbody. This is to be expected since the wakes should have a different behaviour. In figure 16, the total pressure coefficient is shown for a plane $100 \mathrm{~mm}$ behind the vehicle rear end for curve radius $200 \mathrm{~m}$. At the lower part, the wakes look similar, however, at the top the structure differs significantly due to the exterior shape. The wake of the squareback is larger due to the size of the base area.

In figure 17 the lift force coefficient are shown for notchback and squareback turning left. As for the drag, the lift force changes similarly between the curve radiuses. However, it can be noted that, for all radiuses investigated, the lift of the squareback is lower than for the straight-ahead case. Furthermore, for the smallest radiuses (100 and $200 \mathrm{~m}$ ) the difference from the straight-ahead case is larger for the squareback then for the notchback. For the notchback there is an approximate difference of 50 counts but for the squareback the difference is approximately 80 counts. Studying the lift force on the front and rear wheels respectively (figure 18), it can be noted that the forces behave similar for both geometries. Once again a negative force (directed downwards) is obtained at the front wheels and a positive force (directed upwards) is obtained at the rear wheels. It is also noted that the lift forces for the respective geometries differs similarly from their straight-ahead value at the front wheels. However, at the rear wheels, the squareback differs more from the straight case then the notchback, which explains the difference noted for the overall lift force.

Figure 19 shows, as for both drag and lift, that the change in side force is similar between the curve radiuses. However, the squareback is more sensitive to decreasing the curve radius considering the side force. In figure 21 the accumulated side force for the notchback and squareback are shown. Note that the side force is defined positive outwards from centre of rotation. It is at the rear, where the geometries differs, that the side force also differs. This is most clear for small corner radiuses. In figure 20 the pressure coefficient is shown for the left side of both geometries for corner radius $100 \mathrm{~m}$. A major diffference can be seen when comparing the lower, rearmost parts. For the notchback a high pressure area is obtained explaining some of the difference. Further investigations of the pressure and the accumulated side force indicates that there is a change of sign for the side force somewhere along the notchback. Examining the yaw moment (moment around axis through centre of gravity and aligned with $z$-axis) the notchback experience a larger moment then the squareback for all curve radiuses.
$C_{L}$ for front and rear wheels, [counts $C_{L}$ ]
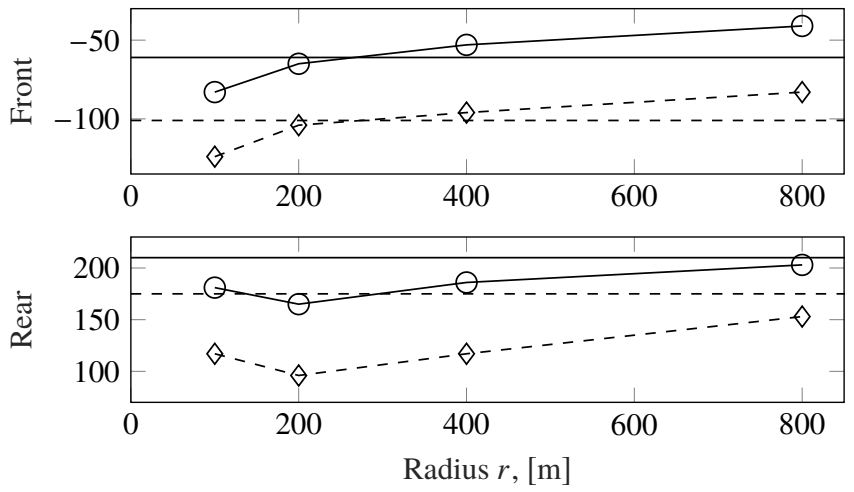

Figure 18: Lift force coefficients for all cornering radiuses for the notchback and the squareback split between the front and rear wheels. The horizontal lines are the straight-ahead cases.

$C_{S}$ notch- and squareback compared to straight

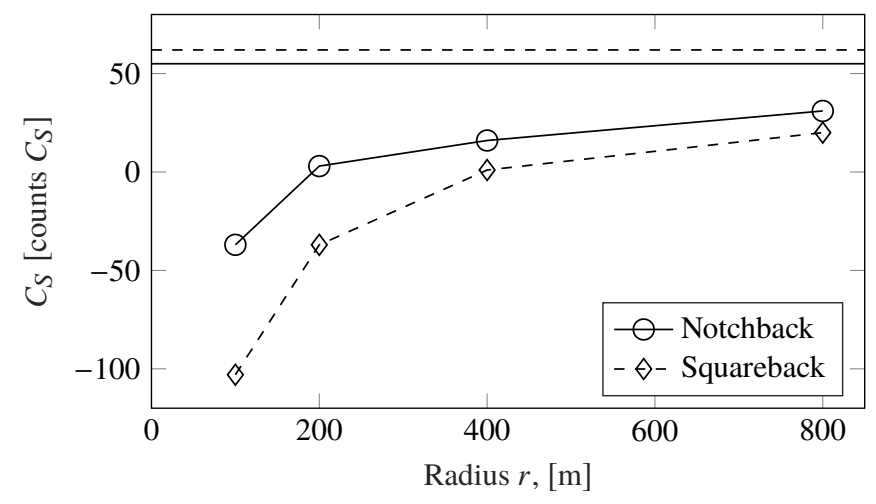

Figure 19: Side force coefficient for notchback and squareback turning left in al curve radiuses. The side force is defined positive out from the center of rotation.

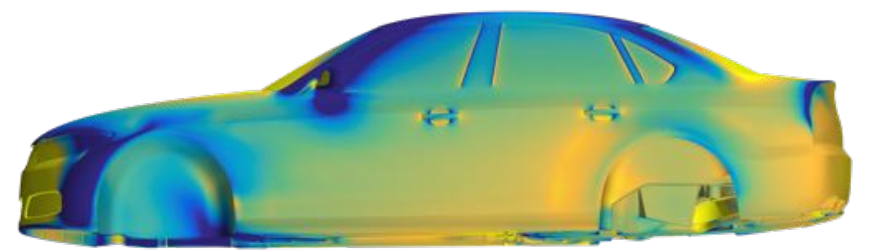

(a) Notchback

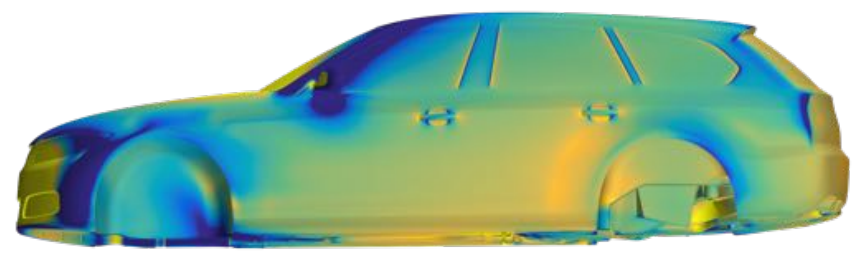

(b) Squareback



Figure 20: Pressure coefficient on the left side of the notchback (a) and the squareback (b) for corner radius $100 \mathrm{~m}$. 
Accumulated side force coefficient, $C_{S}$, for notch- and squareback

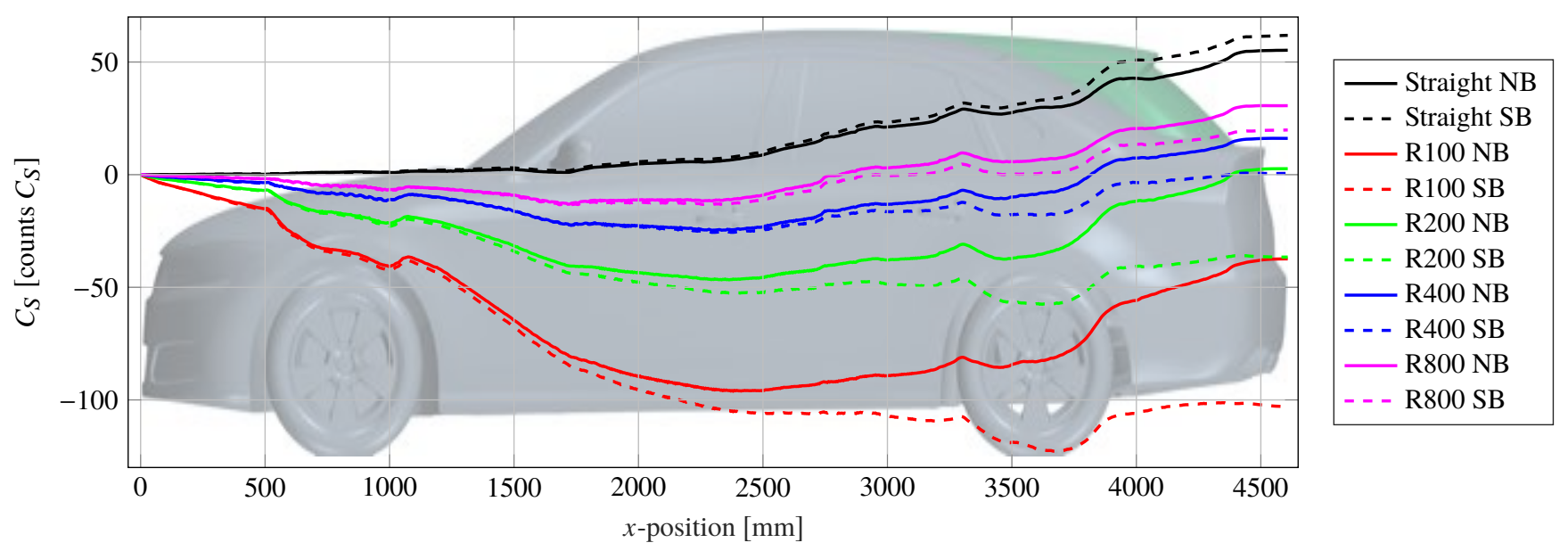

Figure 21: The accumulation of side force for straight ahead driving and all corner radiuses investigated for the notch- and squareback.

\section{Conclusions}

The effects of cornering on the aerodynamics of passenger vehicles has been studied numerically for several corner radiuses and for two vehicles types: a notchback and a squareback. From this study, the following can be concluded:

- Turning affects the flow significantly, however this has been seen before. This is most clear for symmetric parts of the car.

- Underbody asymmetries in the vehicle have an impact on the drag of as much as $11.6 \%$ between the turning directions in curve radius $400 \mathrm{~m}$.

- The underbody has a significant impact on the flow.

- For some turns basic aspects such as drag, lift and side force are more favorable for the driver then in the straight ahead case.

- Comparing the notch- and the squareback has shown that they react similarly to cornering, apart from some differences in side force, where the squareback is more sensitive to reducing curve radius.

- An increase in drag of $9.7 \%$ was noted for a notchback turning right in curve radius $400 \mathrm{~m}$ compared to strght-ahead.

- It might be interesting for car manufactures to include turning in the design process since it significantly affects characteristics such as lift and side force.

\section{References}

[1] "Road transport: Reducing CO2 emissions from vehicles", European Commision, https://ec.europa.eu/clima/policies/transport/ vehicles_en, visited on 05/05/2017.

[2] “WLTP”, European Automobile Manufacturers Association, http: // wltpfacts . eu / what - is - wltp - how - will - it - work, visited on 12/03/2017.

[3] Keogh, J., Doig, G., Diasinos, S., and Barber, T., "The influence of cornering on the vortical wake structures of an inverted wing", Proceedings of the Institution of Mechanical Engineers, Part D: Journal of Automobile Engineering 229(13): 1817-1829, 2015, ISSN: 09544070, DOI: 10.1177/0954407015571673.
[4] Keogh, J., Barber, T., Diasinos, S., and Doig, G., "Techniques for Aerodynamic Analysis of Cornering Vehicles", SAE Technical Paper, 2015, Dor: 10.4271/2015-01-0022.

[5] "DrivAer Model", Technical University of Munich, http://www. drivaer.com/, visited on 02/02/2017.

[6] "How big should the domain be around the car for an external aero case?", Siemens, https://thesteveportal.plm.automation.siemens. com, visited on 03/20/2017.

[7] Jacobson, B., "Vehicle Dynamics. Compendium for Course MMF062”, (Chalmers University of Technology, 2015).

[8] Milliken, W. F. and Milliken, D. L., "Race car vehicle dynamics", (Warrendale, Pa, SAE International, 1995), ISBN: 1-56091-526-9.

[9] "Governing Equations in Moving Reference Frames", Siemens, https://documentation.thesteveportal.plm. automation. siemens. com/, visited on 01/13/2018.

\section{Contact Information}

Erik Josefsson

erikjos@student.chalmers.se

Robin Hagvall

robhagv@student.chalmers.se

Magnus Urquhart

magnus.urquhart@chalmers.se

Simone Sebben

simone.sebben@chalmers.se

\section{Acknowledgements}

Thanks to Aliki Berndtsson, Filip Ljunqvist, Love Roos and Mattias Persson for many hours spent on the bachelor thesis upon which this study is built.

The simulations were performed on resources at Chalmers Centre for Computational Science and Engineering (C3SE) provided by the Swedish National Infrastructure for Computing (SNIC). 


\section{Appendix}

\section{A - Force Coefficients}

In table A1 all force coefficients for all simulations conducted are shown.

Table A1: Force coefficients (in counts) for all simulations performed during the study.

\begin{tabular}{llcrrr}
\hline Configuration & $\begin{array}{l}\text { Turning } \\
\text { direction }\end{array}$ & Radius $[\mathrm{m}]$ & $C_{D}$ & $C_{S}$ & $C_{L}$ \\
\hline Notchback & Straight & - & 288 & 55 & 149 \\
& Left & 100 & 301 & -37 & 98 \\
& & 200 & 282 & 3 & 100 \\
& & 400 & 283 & 16 & 132 \\
& Right & 800 & 287 & 31 & 162 \\
& & 100 & 322 & 69 & 156 \\
& & 400 & 308 & 62 & 185 \\
& & 800 & 316 & 70 & 253 \\
Squareback & Straight & - & 293 & 62 & 223 \\
& Left & 100 & 313 & -103 & 74 \\
& & 200 & 288 & -37 & -8 \\
& & 400 & 285 & 1 & 21 \\
& & 800 & 292 & 20 & 69 \\
& Right & 200 & 310 & 83 & 110 \\
Notchback flat underbody & Left & 200 & 218 & -39 & -18 \\
& Right & & 219 & 45 & -13 \\
\hline
\end{tabular}

